\title{
Sert veya ankilozlu dizlerde total diz protezi uygulaması
}

\author{
Total knee arthroplasty in stiff or ankylosed knees
}

\author{
Bülent Özkurt, Ali Utkan
}

SBÜ Ankara Şehir Hastanesi, Ortopedi ve Travmatoloji Kliniği, Ankara

Sert veya ankilozlu bir dizde diz protezi prosedürü uygulamak zorlu bir işlemdir. Diz sertliği birçok nedene bağ $\left.\right|_{ı}$ gelişmiş olabilir ve bu nedenlerden bazıları tedavide ek zorluk ve risklere neden olur. Yeterli bir cerrahi açılım sağlanamamasındaki zorluklar teknik hatalara ve buna bağlı komplikasyonlara yol açabilir. Ayrıca, aşırı yumuşak doku gevşetmesi yapılması da ilave komplikasyonlara neden olabilir. Bu nedenle çok dikkatli ve nazik bir disseksiyon yapılması gereklidir. Ameliyat öncesi sertliğin nedenleri analiz edilmeli ve cerrah tüm cerrahi tekniklere aşina olmalı fakat en rahat olduğu tekniği seçmelidir. Sertliğin derecesi ve nedeni klinik sonucu etkiler, bu nedenle hastanın önceden gerçekçi beklentilere sahip olmasını sağlamak için tedavi bitiminde beklenen klinik sonuç ve olası komplikasyonlar, basit ve net terimler kullanılarak başlangıçta hastaya açılanmalıdır. Tüm hastalarda agresif bir ameliyat sonrası rehabilitasyon protokolü izlenmelidir. Bu hastalarda ancak optimalin altında bir klinik ve fonksiyonel sonuç elde edilebilmesine rağmen, hastaların ağrı ve fonksiyonel skorlarındaki iyileşme dikkat çekicidir ve hastalar için daha iyi bir yaşam kalitesi sağlanır.

Anahtar sözcükler: diz; sertlik; ankiloze; tedavi; total diz protezi otal diz protezinin (TDP) amacı, iyi hizalanmış, stabil, hareketli ve ağrısı bir diz eklemi elde etmektir. Bu hedeflere çoğu hastada ulaşılır ve normal eklem hareket açıklığına sahip ağrısız bir diz eklemi elde edilir. Ancak ameliyat sonrası ulaşılabilen eklem hareket açıklığı genellikle ameliyat öncesi hareket açıklığı ile ilişkilidir. ${ }^{[1-7]} \mathrm{Bu}$ nedenle, sert dizlerde uygulanan diz protezi ile normale yakın bir ameliyat sonrası hareket açıklığı elde etmek çoğu kez mümkün olmayabilmektedir.

Günlük aktiviteleri yerine getirmek için gerekli hareket açıklığına olanak sağlamayan dizler sert veya sıkı bir diz olarak kabul edilir ve genellikle $50^{\circ}$ 'den daha az hareket açıklığına sahiptirler. ${ }^{[2,4,8-11]}$ Bazı yazarlar
Performing a knee arthroplasty procedure in a stiff or ankylosed knee is a challenging procedure. Knee stiffness could be due to various causes, some of which may involve additional difficulties and risks in the treatment. A failure to obtain an adequate exposure may lead to technical errors and related complications, on the other hand an extensive soft tissue release may lead to complications and very careful and gentle dissection is required. The causes of preoperative stiffness should be analyzed and the surgeon should be familiar with all the surgical techniques but should choose whichever technique he/she is most comfortable. The severity and the cause of the stiffness affect the clinical outcome thus the expected result and possible complications should be initially explained to the patient using simple, clear terms to ensure the patient has realistic expectations in advance. An aggressive post-operative rehabilitation protocol should be followed in all patients. Although a less than optimal clinical and functional outcome can be achieved in these patients, the improvement in the pain and functional scores of the patients is striking and a better quality of life is provided for the patients.

Key words: knee; stiffness; ankylosed; treatment; total knee arthroplasty

ise ekstansiyon sınırına bakılmaksızın $90^{\circ}$ 'den daha az fleksiyona gelebilen veya $20^{\circ}$ 'den fazla ekstansiyon kısıtlılığı olan diz eklemlerini bu grupta değerlendirmiştir. ${ }^{[5,12-15]}$ Etkili cerrahi tekniklere ve yeni geliştirilen protez modellerine rağmen, altta yatan problemler nedeniyle, bu hastalarda elde edilen fonksiyonel sonuçlar genellikle ameliyat öncesi eklem hareket açıklığı normale yakın olan hastalarla ulaşılanlardan daha kötüdür. Ayrıca bu hastalarda daha sık komplikasyon görülmektedir. Öte yandan bu hastalarda standardın altında klinik ve fonksiyonel sonuçlara ulaşılabilmesine rağmen hastaların hayat kalitelerindeki önemli iyileşme nedeniyle memnuniyet oranları oldukça fazladır. ${ }^{[15,16]}$ Artrodez ameliyatı yapılmış,

iletişim / Contact: Prof. Dr. Bülent Özkurt • E-posta / E-mail: drbulentozkurt@yahoo.com

ORCID iD: Bülent Özkurt, 0000-0002-6135-1870 • Ali Utkan, 0000-0002-3653-3998

Geliş / Received: 10 Temmuz 2021 • Kabul / Accepted: 4 Ağustos 2021 


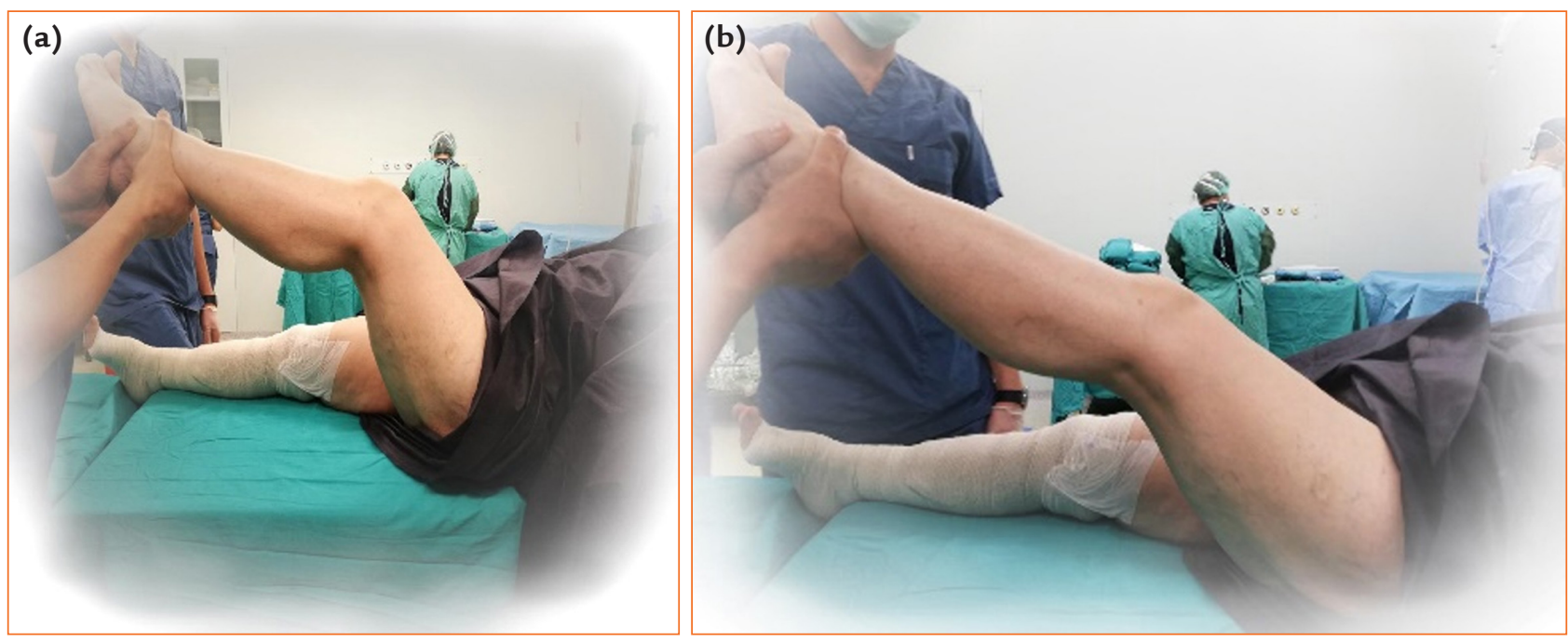

Şekil 1. a, b. Romatoid artrit tanılı 67 yaşında kadın hastanın anestezi altında yapılan muayenesinde diz pasif olarak ancak $40^{\circ}$ fleksiyona alınabiliyor (a), $20^{\circ}$ ekstansiyon kısıtlılı̆̆ı mevcut (b).

veya çeşitli nedenlerle uygun pozisyonda ankiloz gelişmiş ağrısız bir diz eklemine sahip hastalarda protez uygulanması tartışmalı bir konu olsa da bu hastalarda daha da düşük klinik ve fonksiyonel skorlar elde edilmesine ve hastaların zaman zaman diz ağrısından yakınmalarına rağmen sonuçtan genellikle hoşnut oldukları bildirilmektedir. ${ }^{[7,8,17]}$

Sert veya artrodezli dizi olan bir hastada ameliyat kararı alınmadan önce hastanın beklentisi iyi değerlendirilmeli, beklentisinin makul ve gerçekçi olduğundan emin olunmalıdır. Ameliyat öncesi eklem hareket açıklığı ve kontraktür mevcudiyetine bağlı olarak her hastada ameliyat sonrası farklı fonksiyonel sonuçlar elde edildiği ve ameliyat sonrası rehabilitasyon süreçlerinin farklı olduğu hastalara iyi anlatılarak daha sonra gelişebilecek hayal kırıklığının önüne geçilmelidir.

\section{ETIYOLOJi}

Diz sertliği sadece fleksiyon, sadece ekstansiyon veya her ikisinin de kısıtlılığına bağlı olabilir. Eklem hareket açıklığı, travma, diz eklemine uygulanan operasyonlar, septik artrit, tedavisi uygun yapılamamış romatizmal hastalıklar veya agresif osteoartrit nedeniyle azalmış olabilir (Şekil 1).[14,18] Enfeksiyona bağlı gelişen enflamatuvar cevap nedeniyle sinovyal yapışılıklar gelişebilir. Septik artrit suprapatellar bursanın ve eklem kapsülünün kalınlaşmasına ve progresif artrofibroza neden olarak ekstansiyondan çok fleksiyon kısıtlılığına neden olur. Hemofili hastalarında sık görülen eklem içi kanama, kıkırdak hasarı ve sinovyal yapışıklıklara neden olur. Bunun sonucunda gelişen kas atrofileri diz ekleminin stabilitesini azaltarak eklemi streslere karşı savunmasız bırakır ve mikro kırıklar oluşur. ${ }^{[19]}$ Kırık sekelleri hem fleksiyon hem de ekstansiyon hareket genişliğini etkiler. Romatoid hastalıklarda tedavi edilmezse sinovyal kalınlaşmayla başlayıp eklem destrüksiyonuna kadar giden bir süreç vardır. Osteoartritin ilerleyen evrelerinde osteofitlere bağlı sıkışma eklem hareket açıklığını etkiler ve yumuşak doku kontraktürleri gelişebilir. ${ }^{[20]}$

Kontraktür arka kapsülü, kollateral bağları ve ekstansör mekanizmayı içerir. Posterior osteofitler kapsül retraksiyonun neden olarak ekstansiyonu kısıtlarken kuadriseps kası ve hoffaya olan yapışıklıklar fleksiyonu sınırlar. Düzeltilemeyen kontraktürler, hastanın yürüme yeteneğini etkiler ve oluşan ortam enflamasyona ve kontraktürün artmasına neden olur. Ayrıca, aynı taraf kalça patolojisi veya kontraktürü, aynı taraf ayak ve ayak bileği deformiteleri, nörojenik hastalıklara bağı kas spazmı, eklem çevresi kırıklara bağlı yapışıklıklar, geçirilmiş ekstansör mekanizma yaralanmaları, heterotrofik ossifikasyonlar, insizyon ve yara skarları, yanıklar, sistemik hastalıklar, morbid obezite ve uzunluk farkı gibi diz dışı nedenler de sıkı dize neden olabilir. $[7,8,10,12,14,19,21]$

\section{OLASI KOMPLIKASYONLAR}

Sert dizlerdeki asıl teknik sorun, rutin cerrahi yaklaşımla eklemi açığa çıkarmanın zorluğundan kaynaklanmaktadır. Ayrıca cerrahi yaklaşım sırasında yumuşak dokuların aşırı gevşetilmesi nedeniyle protez uygulanırken yumuşak doku ve bağ dengesinin sağlanması zorlaşmaktadır. Daha fazla yumuşak doku disseksiyonu 

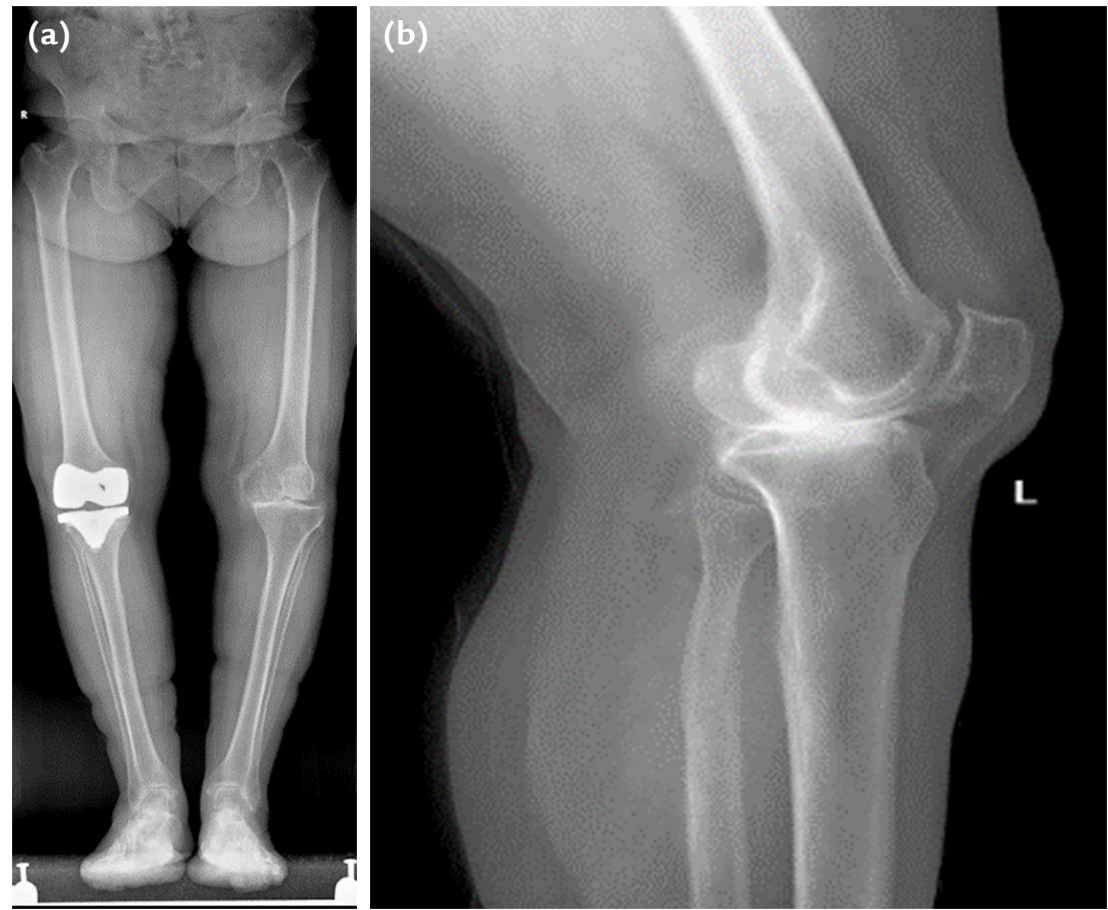

Şekil 2. a, b. Ayakta çekilen ön-arka (AP) uzunluk grafisi (a), sol diz yan grafisi (b).

yapmak gerektiği için cilt nekrozu görülme riski fazladır. Patellar tendon avülsiyonu, ekstansör mekanizma hasarı, fibular sinir hasarı ve tibial komponentlerin iç rotasyonda yerleştirilmesi de bu hastalarda daha sık görülmektedir. ${ }^{[4,7,21]}$ Ameliyat öncesi fleksiyon kısıtlılığı olan hastalarda, ekstansiyon kısıtlılığı olanlara göre eklem açıklığının kazandırılmasının daha zor olduğu rapor edilmiştir. ${ }^{[2,22]}$

\section{TEDAVI ÖNCESI PLANLAMA}

Basarak ön-arka ve yan diz grafileri yanında alt ekstremite ortoröntgenogramları da çektirilmeli ve koronal düzlemde izlenen deformitelerle birlikte sagittal düzlemdeki deformiteler de göz önüne alınmalıdır (Şekil 2). Fleksiyon kontraktürü varlığında önarka grafilerin aldatıcı olabileceği unutulmamalı ve mümkün olduğunda üç boyutlu bilgisayarlı tomografi görüntüleri elde edilerek rotasyonel deformiteler incelenmelidir. Ayrıca Rosenberg grafisi, tanjansiyel grafi, manyetik rezonans (MR) görüntüleme, doku sertliğinin kantitatif değerlendirilmesine olanak veren MR görüntüleme, elastografi, kapillerografi istenmesi önerilmektedir. ${ }^{[7,14,20,23]}$ Bu sayede komşu nörovasküler yapıların ve yumuşak dokuların ve yapışıklıkların tam bir değerlendirmesi yapılarak olası komplikasyonlar en aza indirilebilir.
Eklem içi ve eklem dışı sebepler tespit edilerek ihmal edilmeden hepsinin bir bütün olarak tedavisi amaçlanmalıdır. Bu hastalarda önceki travma veya ameliyatlara bağlı olarak değişik cilt insizyonları ve yapışıklıkları mevcut olabilir. Bu nedenle cilt dikkatli incelenerek mutlaka cerrahi öncesi iyi bir planlama yapılmalı, plastik cerrahi görüşüne de başvurularak, gereğinde protez uygulamasından önce yumuşak doku genişleticileri ile cerrahi insizyonun yapılacağı uygun bir cilt ve cilt altı dokusu elde edilmelidir. ${ }^{[24]}$

Uzun süre fleksiyon kontraktüründe kalan hastalarda ekstansör mekanizmada gelişen uzama, ameliyat sonrası dönemde fleksör kas güçsüzlüğü ve tam ekstansiyona getirememeye neden olduğundan özellikle genç hastalarda protez öncesi kontraktürün düzeltilmesi önerilmektedir. ${ }^{[24]}$

\section{CERRAHI TEKNIK}

Uzatılabilir bir orta hat anterior cilt insizyonu tercih edilmelidir. Daha önceden yapılan ameliyatlara ait skarlar varsa, eklemi açığa çıkarabilecek en lateraldeki eski insizyon hattı üzerinden girilerek medialdeki vasküler yapılar korunmalı ve yapışıklıkların olmadığı normal anatomik yapılara ulaşabilecek kadar uzatılmalıdır. Cilt insizyonunun diz fleksiyondayken yapılması kolaylık sağlamaktadır. 

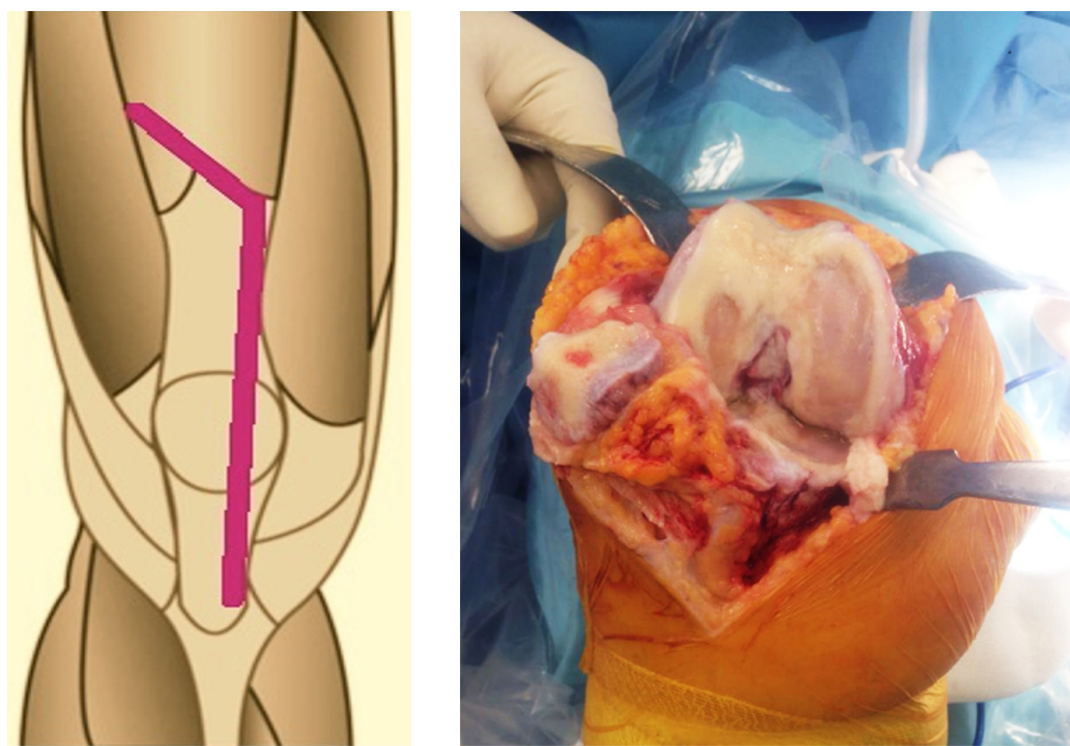

Şekil 4. Sıkı diz olmasına rağmen dizin medial ve lateral gutterları ortaya çıkarılmış.

Şekil 3. Kuadriseps snip kesisi.

Midvastus yaklaşım önerenler olsa da geleneksel olarak dizin rahat ortaya konulabilmesi için parapatellar artrotomi önerilmektedir. ${ }^{[14,18,25]}$ İnsizyon proksimalde Insall'ın tarif ettiği, vastus lateralis kasına $45^{\circ}$ açıyla uzanan ve kuadriseps tendonunun proksimal ve lateralinde sonlanan, kuadriseps snip adı verilen kas kesisine imkân verecek şekilde yapılmalıdır (Şekil 3). Patellayı aşağıya devirecek şekilde ters $V$ şeklinde kuadriseps tendonundan yapılan kesi günümüzde çok kullanılmamaktadır. Bu yaklaşımla, ters $\mathrm{V}$ şeklindeki kesiyi ters Y şekline çevirerek, hem kuadriseps tendonu uzatılmış hem de çok geniş̧ bir açııım sağlanmış olur.

Tabaka tabaka gevşetme yapılarak ilerlemeli ve vasküleritenin korunmasının şart olduğu unutulmamalıdır. Varus veya valgus deformitelerini düzeltecek uygun yumuşak doku gevşetmeleri yapılmalıdır. Suprapatellar bölgedeki fibröz yapışıklıklar eksize edilerek dizin medial ve lateral gutterları ortaya tam çıkarılmalıdır (Şekil 4). Tibia proksimalinde pes anseriusa kadar subperiosteal gevşetme yapılarak gereğinde semimembranöz tendonu yapışma yerinden kesilmeli, patellar tendon ve altındaki fibrotik dokular serbestleştirilmelidir. Gerekli ise, patellar küçültme ameliyatın erken aşamalarında yapılmalıdır. Mevcutsa ön çapraz bağ (ÖÇB) ilk olarak kesilmelidir. Kuadriseps tendonu ve patellar tendon çevresindeki tüm yapışıklıkların açıldığından emin olunduktan sonra diz tekrarlayan fleksiyon hareketleriyle hafiften başlayıp gittikçe zorlayarak ekstansör mekanizma gerdirilmelidir. Bu sırada patellar tendonun kopmaması için azami dikkat gösterilmeli, gereğinde tendonun medial tarafından uygulanacak geçici bir çivi (pin) veya klips tespiti uygulanarak ek bir koruma sağlanmalıdır. Yeterince fleksiyon elde edilemediyse öncelikle prepatellar yağ yastıkçığının lateral tarafının tam gevşetildiğinden emin olunmalı, lateral patellofemoral ligamentler kesilmeli ve lateral retinaküler gevşetme yapılmalıdır. Gereğinde lateral kollateral ligament ve popliteus tendonu femurdan subperiosteal olarak sıyrılmalı ve iliotibial bant $Z$ şeklinde kesilerek uzatılmalıdır. Tüm bu yapılan gevşetmeler sonrasında yeterli fleksiyon elde edilemezse kuadriseps snip veya tibial tüberkül osteotomisi yapılmalıdır. ${ }^{[26,27]}$

Kemik kesileri yapılırken hem femur hem de tibiadan eşit oranlarda kemik rezeksiyonu yapıldığından ve hem fleksiyonda hem de ekstansiyonda eşit boşluk oluşturulduğundan emin olunmalıdır. Fleksiyon kontraktürü olan hastalarda, genellikle, fleksiyondaki boşluk normalken ekstansiyonda aralığın daraldığı görülür ve bu fleksiyon kontraktürünün düzeltilemediği anlamına gelir. Bu durumda daha çok yumuşak doku gevşetmesi yapılmalı veya distal femoral rezeksiyon miktarı artırılmalıdır. Bazı yazarlar ise tibiadan daha fazla rezeksiyon yapılarak fleksiyon boşluğunun artırılmasını ve daha büyük boy femoral komponent kullanımını önermektedirler. ${ }^{[14]}$

Ameliyat sonrası kalan (rezidüel) fleksiyon kontraktürü enerji harcamasını çok artırarak klinik fonksiyonu ve hasta memnuniyetini çok azaltır. Posterior osteofitlerin temizlendiğinden emin olunmalıdır. Fleksiyon kontraktür varlığında kollateral ligament ve posterior kapsülün kısalmış olduğu unutulmamalı ve posterior 


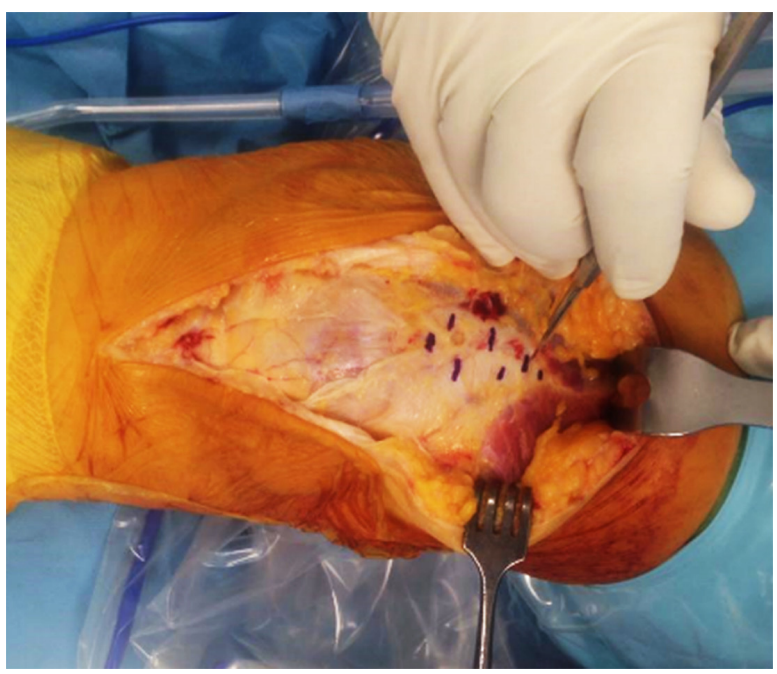

Şekil 5. Pie-crusting tekniğinin uygulanması.
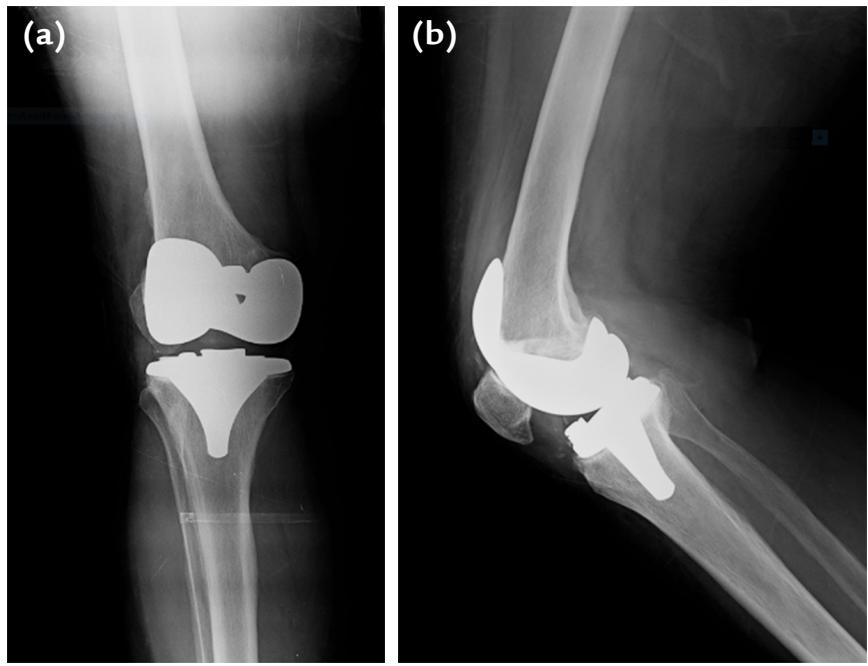

Şekil 6. a, b. Ameliyat sonrası ön-arka (AP) grafi (a) ve yan grafi (b). kapsül gevşetilmelidir. Gevşetmenin yetersiz kaldığı düşünülürse popliteus, hamstring kasları insersiyoları ve gastreknemius kası origosu gevşetilmelidir.

Diz fleksiyon pozisyonunda arka çapraz bağ (AÇB) uzamış pozisyonda olduğu bilinmesine rağmen fleksiyon kontraktürü varlığında AÇB kesen protez tasarımlarının kullanımı tercih edilmelidir. Agresif yumuşak doku gevşetmesi veya femoral rezeksiyonun fazla yapılması nedeniyle kollateral bağların hasar gördüğü durumlarda kısıtlayıcı protezler tercih edilmelidir. ${ }^{[28]}$

Protez yerleştirildikten sonra fleksiyon açıklı̆g yeterli bulunmazsa pie-crusting olarak bilinen ve diz fleksiyon kontraktürlerinin tedavisi için perkütan olarak tarif edilen kuadriseps tendonunun gevşetme tekniği kullanılabilir (Şekil 5 ve 6). ${ }^{[1]}$

\section{Ankilozlu Diz}

Eğer patella oynamıyorsa öncelikle osteotomi yapılarak patella femurdan ayırılmalıdır. Ankilozlu dizlerde eklem çizgisini ve patellanın eklemle ilişkisini belirlemek zordur. ${ }^{[7]}$ Kemik füzyon olsa bile ÖçB'nin artıkları yol gösterici olabilir. Transepikondiler aks geçirilen bir Kirschner teli (K-teli) işaret yardımıyla radyografik olarak doğrulandıktan sonra, anteriordan 1 cm'lik bir kama çıkartılmalıdır. Fibröz ankilozlu dizlerde ise dikkatli bir disseksiyonla eklem açığa çıkartılır. Nörovasküler yapıları korumak için diz fleksiyona alınarak kemik kesiler yapılmalıdır. Kesilerden sonra posterior yumuşak doku gevşetmesi yapılmalı fakat stabilitenin korunması için yeterli bir kılıf bırakılmalıdır. Bu hastalarda eklem açıklığı egzersizlerine en az altı ay devam edilmelidir. ${ }^{[7]}$

\section{Ameliyat Sonrası Dönem/Süreç}

En az cerrahi aşama kadar önemlidir. Multimodal ağrı kontrolü ile beraber agresif bir rehabilitasyon programına hemen başlanılması önerilmektedir. Epidural veya periferik sinir blok kateterleri ile ameliyat sonrası sürekli analjezi uygulamalarının yardımı olmaktadır. Hastalar ameliyat sonrası erken dönemde daha rahat ettikleri için dizlerini fleksiyon pozisyonunda tutma eğilimindedirler. Hasta, hasta yakınları ve klinik personeli bu konuda eğitilerek gereğinde topuk altına konan ufak yastıklar yardımıyla dizin aktif ekstansiyonu teşvik edilmelidir. Rezidüel fleksiyon kontraktürü kalan veya harmstring kaslarında spazm olan hastalarda dizi ekstansiyonda tutacak çıkartılabilir bir atel veya ortez kullanılabilir. Pasif eklem hareket açıklığı egzersizlerine hemen başlanmalı, hasta tolere ettiğinde de düz bacak kaldırma ve yardımla yürümeye başlanmalıdır. Fakat ameliyatta $V-Y$ kuadrisepsplasti uygulanan hastalar bu programın dışında tutulmalı, eklem hareket açıklığı egzersizleri geciktirilerek kilitli dizlikler yardımıyla fleksiyon sınırına altı haftada ulaşılmalıdır. Hastalar taburcu edildikten sonra da ev egzersiz programlarına devam etmelidirler.

\section{SONUÇ}

Sert dizde yapılan protez uygulamaları teknik olarak sıkıntılı ve komplikasyonlara açıktır. Ameliyat öncesi dikkatli bir klinik değerlendirme ile iyi bir planlama yapılmalı, hasta ve yakınları ameliyat ve sonrası gelişebilecek sorunlar hakkında ayrıntılı bilgilendirilmelidir. Geniş yumuşak doku gevşetmesi ihtiyacı çok 
dikkatli ve nazik uygulama gerektirir. Ameliyat öncesi mevcut kısıtlı diz hareket genişlikleriyle doğru orantılı olarak ameliyat sonrası kazanılan diz hareket genişlik oranları normal sınırların altında kalmakla birlikte, hastaların yaşam kaliteleri arttığı için, hastaların memnuniyet oranları genellikle yüksektir. Bununla birlikte hastaların olası klinik sonuç hakkında gerçekçi beklentilerinin olduğundan ve alınmış onamlarda bu konunun açıkça yazılmış olduğundan emin olunmalıdır.

\section{KAYNAKLAR}

1. Aglietti P, Windsor RE, Buzzi R, Insall JN. Arthroplasty for the stiff or ankylosed knee. J Arthroplasty 1989;4(1):1-5. Crossref

2. Fosco M, Filanti M, Amendola L, Savarino LM, Tigani D. Total knee arthroplasty in stiff knee compared with flexible knees. Musculoskelet Surg 2011;95(1):7-12. Crossref

3. Gatha N, Clarke H, Fuchs R, Scuderi G, Insall J. Factors Affecting Postoperative Range of Motion After Total Knee Arthroplasty. J Knee Surg 2010;17(4):196-202. Crossref

4. Khatri D, Malhotra R, Bhan S, Kumar V, Eachempati KK. Comparison of Total Knee Arthroplasty in Stiff Knees and Knees with Good Preoperative Range of Motion. J Knee Surg 2009;22(4):305-9. Crossref

5. Lee SA, Kang S-B, Chang CB, Chang MJ, Kim YJ, Song MK, Jeong $\mathrm{JH}$. Does the severity or cause of preoperative stiffness affect the clinical results and range of motion after total knee arthroplasty? PLoS ONE 2018;13(10):e0205168. Crossref

6. McAuley JP, Harrer MF, Ammeen D, Engh GA. Outcome of knee arthroplasty in patients with poor preoperative range of motion. Clin Orthop Relat Res 2002;404:203-7. Crossref

7. Rajgopal A, Ahuja N, Dolai B. Total knee arthroplasty in stiff and ankylosed knees. J Arthroplasty 2005;20(5):585-90. Crossref

8. Bhan S, Malhotra R, Kiran EK. Comparison of total knee arthroplasty in stiff and ankylosed knees. Clin Orthop Relat Res 2006;451:87-95. Crossref

9. Hsu C-H, Lin P-C, Chen W-S, Wang J-W. Total knee arthroplasty in stiff knees. J Arthroplasty 2012;27(2):286-91. Crossref

10. Ranawat CS, Flynn Jr WF. The stiff knee: Ankylosis and Flexion. In: Lotke PA, Lonner JH, editors. Master Techniques in Orthopedic Surgery: Knee Arthroplasty, 3rd ed. Lippincott Williams \& Wilkins, 2009. p.145-58.

11. Montgomery WH 3rd, Insall JN, Haas SB, Becker MS, Windsor RE. Primary total knee arthroplasty in stiff and ankylosed knees. Am J Knee Surg 1998;11(1):20-3. https:// pubmed.ncbi.nlm.nih.gov/9533049/

12. Massin P, Lautridou C, Cappelli M, Petit A, Odri G, Ducellier F, Sabatier C, Hulet C, Canciani J, LetenneurJ, Burdin P; Société d'Orthopédie de l'Ouest (SOO). Total knee arthroplasty with limitations of flexion. Orthop Traumatol Surg Res 2009;95(4 Suppl 1): S1-6. Crossref
13. Debette C, Lustig S, Servien E, Lording, Villa V, Demey G, Neyret P. Total knee arthroplasty of the stiff knee: three hundred and four cases. Int Orthop 2014;38(2):285-9. Crossref

14. Massin P. Total Knee Replacement for the Stiff Knee. In: Bentley G, editor. European Instructional Lectures, Vol. 11. Berlin, Heidelberg: Springer; 2011. p.189-95. Crossref

15. Kim Y-H, Kim J-S. Does TKA improve functional outcome and range of motion in patients with stiff knees? Clin Orthop Relat Res 2009;467(5):1348-54. Crossref

16. Polascik BW, Bin Abd Razak HR, Chong H-C, Lo N-N, Yeo S-J. Acceptable functional outcomes and patient satisfaction following total knee arthroplasty in Asians with severe knee stiffness: a matched analysis. Clin Orthop Surg 2018;10(3):337-43. Crossref

17. Choi Y-J, Seo D-K, Lee KW, Ra HJ, Kang HW, Kim JK. Results of total knee arthroplasty for painless, stiff knees. Knee Surg Relat Res 2020;32(1):61. Crossref

18. Baldini A, Castellani L, Traverso F, Balatri A, Balato G, Franceschini $V$. The difficult primary total knee arthroplasty. J Bone Joint Surg 2015;97-B(10 Suppl A):30-9. Crossref

19. Rodríguez-Merchán EC. Effects of Hemophilia on articulations of children and adult. Clin Orthop Relat Res 1996;(328):713. https://pubmed.ncbi.nlm.nih.gov/8653981/

20. Latke AL, Simon RG. Flexion contracture in total knee arthroplasty. In: Scuderi GR. Tria AJ, editors. Knee Arthroplasty Handbook. New York, NY: Springer; 2006. p.5769. Crossref

21. Cheung A, Goh SK, Tang A, Keng TB. Complications of total knee arthroplasty. Curr Orthop 2008;22(4):274-83. Crossref

22. Rajgopal A, Panda I, Dahiya V. A comparative study on the long-term outcome of total knee arthroplasty performed for knees stiff in extension and those stiff in flexion. J Arthroplasty 2017;32(11):3396-403. Crossref

23. Vanlauwe J, Vandenneucker $H$, Bellemans J. TKA in the stiff knee. In: Bonnin M, Amendola A, Bellemans J, MacDonald S, Ménétrey J, editors. The Knee Joint. Paris: Springer; 2012. p.897-900. Crossref

24. Kelly MA, Clarke HD. Stiffness and ankylosis in primary total knee arthroplasty. Clin Orthop Relat Res 2003;416:68-73. Crossref

25. Shah NA, Patil HG, Vaishnav VO, Savale A. Total knee arthroplasty using subvastus approach in stiff knee: A retrospective analysis of 110 cases. Indian J Orthop 2016;50(2):166-71. Crossref

26. Purcell RL, Goyal N, Engh GA. Extensile exposures for total knee arthroplasty. In: Bono JV, Scott RD, editors. Revision Total Knee Arthroplasty, 2nd ed. Cham.: Springer; 2018. p.75-87. Crossref

27. Eid AS, Nassar WAM, Fayyad TAM. Total knee replacement with tibial tubercle osteotomy in rheumatoid patients with stiff knee. Int Orthop 2016;40(11):2289-93. Crossref

28. Rai S, Liu X, Feng X, Rai B, Tamang N, Wang J, Ye S, Yang $S$. Primary total knee arthroplasty using constrained condylar knee design for severe deformity and stiffness of knee secondary to post-traumatic arthritis. J Orthop Surg Res 2018;13:67. https://doi.org/10.1186/s13018-018-0761-x 